\title{
Urban land expansion and its driving factors of mountain cities in China during 1990-2015
}

\author{
WANG Ziwei ${ }^{1,2},{ }^{*}$ LU Changhe ${ }^{1,2}$ \\ 1. Key Laboratory of Land Surface Pattern and Simulation, Institute of Geographic Sciences and Natural Re- \\ sources Research, CAS, Beijing 100101, China; \\ 2. College of Resources and Environment, University of Chinese Academy of Sciences, Beijing 100049, China
}

\begin{abstract}
Land expansion of mountain cities in China is not systematically studied yet. This study identified 55 major mountain cities at and above prefecture level, and analyzed the land expansion characteristics and driving forces, based on visually interpreted data from TM images in 1990, 2000, 2010 and 2015. From 1990 to 2015, total built-up land area of the mountain cities increased by 3.87 times, $5.56 \%$ per year. The urban land growth was apparently accelerated after 2000 , from $4.35 \%$ per year during $1990-2000$ increased to $6.47 \%$ during 2000-2010 and $6.2 \%$ during 2010-2015. Compared to the urban population growth, the urban land expansion rate was $44 \%$ higher. As a result, the urban land area per capita increased, but it was still within the government control target, and also was much lower than the average of all cities in China. Urban development policy, changes to administrative divisions, GDP and population growth, and road construction were identified as the major driving forces of land expansion. Terrain conditions were not found a relevance to the urban land expansion rate during 1990-2015, but had a significant impact on the layout and shape, and also probably on the urban land efficiency.
\end{abstract}

Keywords: mountain cities; urban land expansion; driving forces; elastic coefficient; city compactness

\section{Introduction}

Since 1990, China's urban land has experienced a rapid expansion and as of the end of 2015, the total area from the statistical data was $40,941 \mathrm{~km}^{2}$, up $311.4 \%$. This quick urban land expansion was not in a synchronous pace with the urban population growth, as the urbanization rate was $56.1 \%$ in 2015 , increasing only by $29.7 \%$ compared to that in 1990 . This illustrated that the urban land expansion was not only driven by urban population growth, but also by other factors such as economic development, transportation infrastructure construction, industrial restructuring, and new district development (Chen et al., 2016; Li et al., 2011; Tan et al., 2005; Zhou et al., 2007).

Received: 2017-10-17 Accepted: 2018-02-08

Foundation: National Key R\&D Plan of China, No.2017YFA0604701; National Natural Science Foundation of China, No.41671093

Author: Wang Ziwei, PhD Candidate, E-mail: wangzw.13b@igsnrr.ac.cn

"Corresponding author: Lu Changhe (C. H. Lu), Professor, E-mail: luch@igsnrr.ac.cn 
For individual cities, the urban land area mostly showed a quick expansion during the past two decades, but the growth rate varied greatly over time and space (Chi et al., 2015; Liu et al., 2016; Tong et al., 2016; Yu et al., 2016). This implies that the pattern and driving mechanism of urban land expansion differed regionally, due to the influence of diversified socio-economic conditions (Huang et al., 2007; Lin et al., 2015; Tan, 2017; Yu et al., 2017). In addition, the terrain and natural resource conditions also exerted a great influence on the urban land expansion (Cao et al., 2016; Li et al., 2016; Zhang et al., 2016), particularly for mountain cities.

In China, two thirds of the territory is mountainous areas and $35 \%$ of the designated cities are mountain cities (Huang, 2006). So far, only a few studies have paid special attention to mountain cities, and discussed issues related to urban land use structure (Guo et al., 2005) and urban planning (Liu, 2009). To understand the development process of mountain cities, we should make a systematic analysis of the urban land expansion and the driving mechanism. Therefore, this study selected the mountain cities at and above prefecture level as the representative to identify the urban growth characteristic and the causes. Firstly, the urban land area for each city was extracted in four representative years of 1990, 2000, 2010 and 2015 by visual interpretation using TM images, and then the urban land expansion rate and its spatio-temporal variation during 1990-2015 were analyzed using index approaches and ArcGIS tools. Finally, the driving factors were identified by ridge regression analyses.

\section{Data and methods}

\subsection{Definition of mountain city and the urban area}

Based on the definition in previous studies (Chen, 2001; Huang, 2006), a city located in mountainous areas is simply identified as a mountain city. The built-up areas of a mountain city are generally distributed in valleys and basins or on gently sloping lands, and mostly surrounded by steep terrain. The urban area includes all the built-up lands within the city districts, the same as the city range defined in the China City Statistical Yearbook. In this study, only the mountain cities at and above prefecture level were studied. From the 295 same-level cities across China, a total of 55 cities were determined as mountain cities, using slope steepness and relative elevation as the major indicators based on the $30-\mathrm{m}$ resolution DEM and imagery data. These mountain cities are mostly distributed in central, southwestern and northwestern China (Figure 1).

\subsection{Extraction of urban land area}

This study selected the years of 1990, 2000, 2010 and 2015 as representatives. The urban area of the mountain cities for each year was extracted using Landsat images and digital elevation data of ASTER GDEMV2. The data, as collected from the Computer Network Information Center, Chinese Academy of Sciences (http://www.gscloud.cn) included Landsat 4-5 TM images in 1989, 1990 and $1991^{1}$, Landsat 7 ETM images in 2000 and 2010, and

\footnotetext{
1 As the images in 1990 were only available for 16 cities (Chenzhou, Hechi, Lishui, Longnan, Lvliang, Mianyang, Shangluo, Shaoguan, Tianshui, Tongren, Weihai, Yan'an, Zigong, Leshan, Yibin, and Zunyi), the urban boundary was delineated using the images in 1989 for 22 cities (Bijie, Dazhou, Fushun, Benxi, Guangyuan, Guiyang, Hegang, Huangshi, Liaoyuan, Lincang, Liupanshui, Longyan, Nanchong, Chongqing, Nanping, Panzhihua, Sanming, Wuzhou, Xining, Yangquan, Yichun, Yichun), and 1991 for other 17 cities.
} 
Landsat 8 OLI images in 2015 at the same spatial resolution of $30 \mathrm{~m}$. The imagery data were imported to ArcGIS to convert to the WGS-84 coordinate system, and then to make the false colored images based on the short-wave infrared band, near infrared band and green band using the Composite Bands tool in ArcGIS. With the colored images, the urban area in each of the four years was interpreted, respectively. In addition, the digital elevation data and Google Earth HD images were used to help determining the boundary when it cannot be clearly identified with the Landsat images. The interpreted urban area for each city in 1990, 2000, 2010 and 2015 was overlapped in sequence using analysis tools in ArcGIS to obtain the urban area changes in 1990-2000, 2000-2010, 2010-2015 and 1990-2015, respectively (Figure 1).

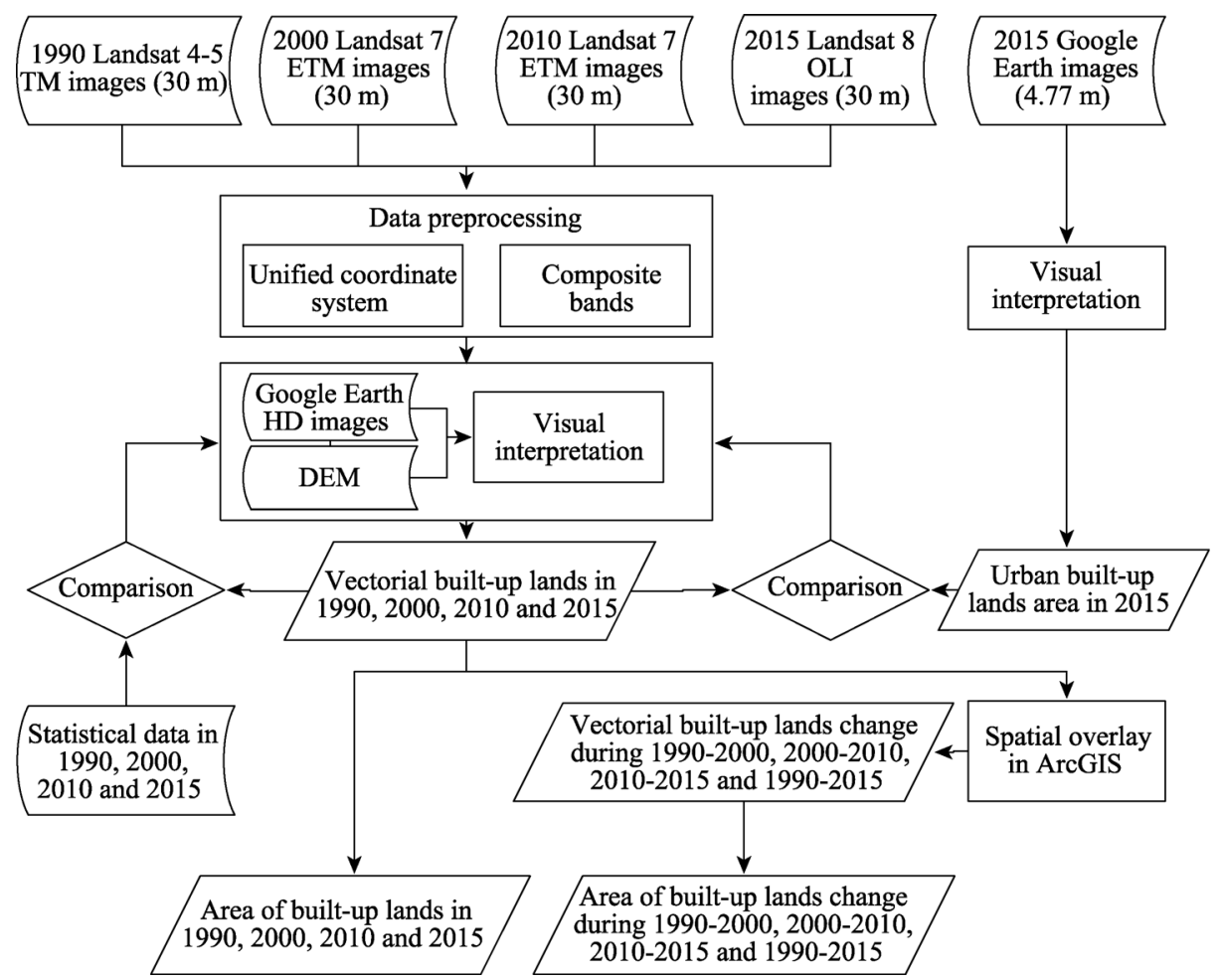

Figure 1 The flowchart of urban land area extraction in the four years and calculation of its changes for the four periods

To examine the accuracy, we downloaded the high resolution color images $(4.77 \mathrm{~m})$ of 2015 from Google Earth for the 55 cities. With these images, we obtained the urban area for each city by visual interpretation. By comparison, the area obtained with the Landsat images in 2015 was overestimated by $0.16 \%-18.26 \%$ for 39 cities and underestimated by $0.26 \%-15.44 \%$ for the other 16 cities. The absolute value of the error was below $5 \%$ for 17 cities, $5 \%-10 \%$ for 16 cities, $10 \%-15 \%$ for 15 cities, and above $15 \%$ for 7 cities. The mean absolute value of the errors was $8.29 \%$ for all cities. Compared with the statistical data reported in the China City Statistical Yearbooks, the interpreted urban area was 23\% lower in 2015, since the statistical data included the lands that obtained the Land Planning Permit and Land Construction Permit, but not constructed yet. In general, the data accuracy could be acceptable for the objective of this study mainly aimed to detect the urban land change dur- 
ing 1990-2015.

\subsection{Methods}

Urban land expansion rate can be quantified using index methods, such as proportion index, extent index, and growth speed index. For the driving mechanism, multi-regression analyses were normally applied (Li et al., 2017; Yu et al., 2017). In this study, three indices were used to characterize the land expansion characteristic of mountain cities, and multi-regression analyses were applied for detection of the driving forces.

\subsubsection{Quantification of urban land expansion}

Annual growth rate of urban land area, the elastic coefficient to urban population growth, and city compactness index were used to describe the land expansion characteristics. For urban land growth rate, it is calculated with the formula below:

$$
R=\left[\left(L_{t} / L_{1}\right)^{1(t-1)}-1\right] \times 100 \%
$$

where $R$ is the annual growth rate (\%) during the study period $t$ (years), and $L_{1}$ is the urban land area $\left(\mathrm{km}^{2}\right)$ at the beginning year and $L_{t}$ at the ending year of the study period.

Elastic coefficient is used to evaluate the coordination degree between urban land and population growths for each city from 1990 to 2015. This widely used coefficient (Yang et al., 2013) is presented as the ratio of mean annual growth rate (\%) of urban land area to that of urban population during a given period (An et al., 2012). Based on the data availability, the urban population data in 1990 were collected from the China City Statistical Yearbook, in 2000 and 2010 separately from the fifth and sixth census data, and in 2015 from the statistical bulletin of the national economic and social development of each city district.

City compactness index is used to characterize the shape of a city (Mizutani, 2012; Pan et al., 2015), by checking degree of the urban built-up area approaching to a circle shape. It is formulated as below:

$$
C=\frac{2 \times \sqrt{\pi \times A}}{P}
$$

where $A$ represents the urban land area $\left(\mathrm{m}^{2}\right), P$ stands the boundary length $(\mathrm{m})$, and $C$ is the compactness index for a city. The compactness index ranges between 0 and 1 . The larger the compactness index is, the closer to a circle the city shape is, and thus the more compact the city is (Liu et al., 2014). In this study, the urban area and its perimeter were calculated using the ArcGIS Calculator for each of the 55 cities in 1990, 2000, 2010 and 2015. For cities comprising several built-up areas, the compactness index was the weighted average of the index of each built-up area that was calculated with the same equation (2).

\subsubsection{Identification of factors affecting urban expansion}

Qualitative analyses were firstly applied to screen out possible factors affecting urban land expansion by literature reviews, and then ridge regressions that can eliminate the multicollinearity influence (Barcena et al., 2014), was used to identify the driving factors and their contribution to urban land change. By preliminary analysis, seven socio-economic factors were considered, including GDP, urban income, urban population, fixed asset investment, foreign investment, urban green land area, and urban road area. The data during 1990-2015 
were collected from China City Statistical Yearbook for 48 mountain cities ${ }^{2}$ with complete available data. In addition, two terrain variables, i.e., slope steepness and elevation for the urban area, and three buffer zones of $500 \mathrm{~m}, 1000 \mathrm{~m}$ and $2000 \mathrm{~m}$ around the city were included for the analysis, with the data computed from the DEM data using ArcGIS. For GDP and income, the values at 2000, 2010 and 2015 were converted to the constant price at 1990 . All variables were normalized using the Napierian logarithm to eliminate the heteroscedasticity (Zhang, 2007), and then regressed using ridge regression approach to identify the relevance degree and contribution to urban land area and the change. The general form of multivariable regression is presented below:

$$
\ln A_{i}=\sum \beta_{i j} \ln V_{i j}+\varepsilon
$$

where $A_{i}$ is the urban land area $\left(\mathrm{km}^{2}\right)$ in a year for city $i, V_{i j}$ is the independent variables involved such as GDP and population, $\beta_{i j}$ is the coefficient of variable $j$, and $\varepsilon$ is residual error. For the analysis of factors affecting the urban land change, the value for the variables is the total change during the given period.

\section{Urban land expansion characteristics of mountain cities}

\subsection{Urban land expansion and its spatio-temporal variation}

The urban built-up land area for all mountain cities, totalling $5047 \mathrm{~km}^{2}$ in 2015 , or $12.32 \%$ of the total built-up area for all cities in China, expanded by $387.01 \%$ in total or $5.56 \%$ per year, compared to that of $1304 \mathrm{~km}^{2}$ in 1990 . Regionally, western China showed the fastest urban land growth of $6.74 \%$ per year, followed by $6.33 \%$ in eastern China and $4.93 \%$ in central China (Table 1). For the mountain cities in northeastern China that are generally resource-based, the urban land showed a very low growth rate, only with an annual rate of $2.17 \%$. At city level, the expansion rate varied greatly from $0.63 \%$ to $9.44 \%$ per year (Figure 2 and Table 2). In 15 cities including Chongqing, Yan'an, Mianyang, Tongren, and Weihai, the urban land area increased by 5.04-9.54 times during the past 25 years, while in 4 resource-based industrial cities of Hegang, Shuangyashan, Benxi and Fushun, the urban area was only increased by $17.1 \%-31.7 \%$.

Table 1 Total urban land area of mountain cities in 1990, 2000, 2010 and 2015 and annual growth rate in different regions of China during 1990-2015

\begin{tabular}{cccccc}
\hline \multirow{2}{*}{ Regions } & \multicolumn{3}{c}{ Urban land area $\left(\mathrm{km}^{2}\right)$} & \multicolumn{2}{c}{$\begin{array}{c}\text { Annual growth rate }(\%) \\
1990-2015\end{array}$} \\
\cline { 2 - 5 } & 1990 & 2000 & 2010 & 2015 & 6.33 \\
Eastern China & 112.97 & 207.89 & 430.71 & 524.62 & 4.93 \\
Central China & 220.32 & 311.88 & 577.21 & 734.27 & 6.74 \\
Western China & 627.42 & 1064.76 & 2251.7 & 3201.00 & 2.17 \\
Northeastern China & 343.57 & 412.04 & 476.12 & 587.82 & \\
\hline
\end{tabular}

Note: Eastern China includes cities in provinces of Hebei, Shandong, Zhejiang, Fujian and Guangdong. Central China includes cities in Shanxi, Henan, Hubei, Hunan and Jiangxi. Northeastern China includes cities in Heilongjiang, Jilin and Liaoning, and western China includes cities in Sichuan, Guizhou, Yunnan, Shaanxi, Gansu, Guangxi and Qinghai and the city of Chongqing.

${ }^{2}$ Due to administrative changes, the socio-economic data during the study period were incomplete for other 7 cities including Lvliang, Tongren, Bijie, Pu'er, Lincang, Longnan and Hechi, thus these 7 cities were excluded for the analysis. 


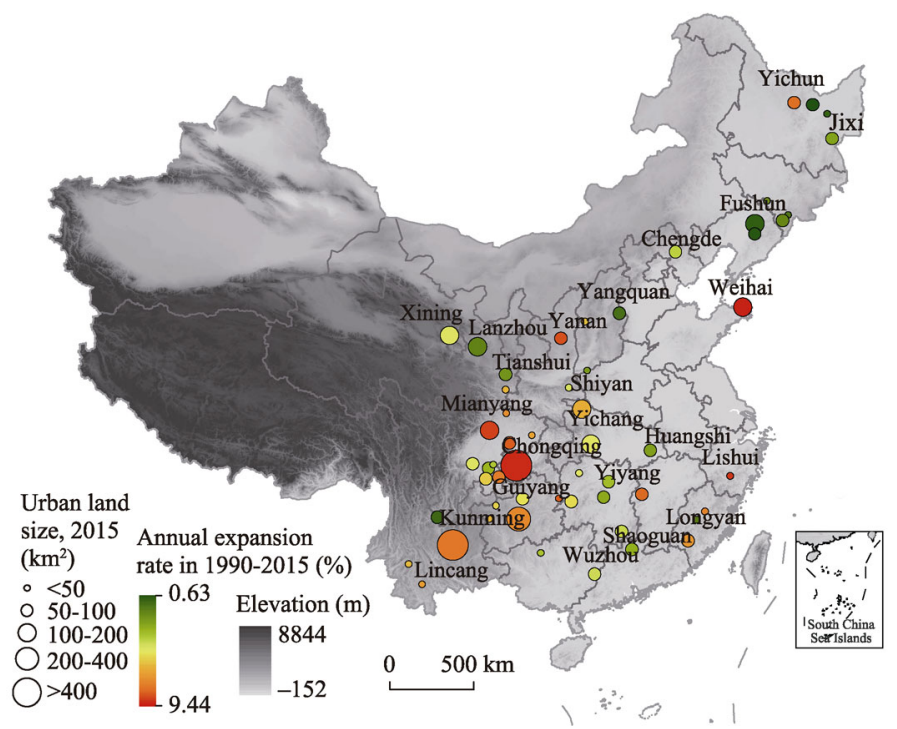

Figure 2 Spatial variation of urban land area and annual expansion rate of mountain cities in China

The mean urban land expansion rate of all mountain cities was $4.35 \%$ per year during 1990-2000, increased apparently to $6.47 \%$ during 2000-2010, and then slightly decreased to $6.2 \%$ during 2010-2015. As for individual cities, the growth rate varied more greatly among the three periods (Table 2), with the greatest expansion not synchronized in the same stage. In 22 cities, the fastest urban expansion occurred in the second period of 2000 to 2010,16 in the first decade, and 17 in the last five years. Several cities showed an abrupt increase in the urban land area, such as Yan'an and Shiyan during 2010-2015, Chongqing, Weihai, Tongren, Lishui, Nanchong and Puer during 2000-2010, and Longyan, Mianyang and Longnan during 1990-2000. This quick increase was largely caused by the administrative adjustment and new district development.

The elastic coefficient of urban land growth to urban population growth during 1990-2015 varied from 0.65 to 6.62 for the mountain cities (Table 2) except two resource-based industrial cities in northeastern China. The elastic coefficient of these two cities showed a negative value, due to the urban population decrease. In 15 cities including Lanzhou and Tianshui, the elastic coefficient was less than 1, as the growth rate of urban land was lower than that of the population, while in 23 and 15 cities the elastic coefficients ranged from 1.01 to 1.50 and above 1.50 , respectively. As a result of the very low population growth, Liupanshui and Jixi showed a very high value of 6.46 and 4.94 (Table 2). Except the two cities with negative values, the mean elastic coefficient for all other cities was 1.44 , implying that mean growth rate of urban land was $44 \%$ higher than that of population, exceeding the rational value of 1.10, as suggested in literature (An et al., 2012; Marshall, 2007).

\subsection{Urban sprawl characteristics}

Figure 3 presents urban land sprawl of all mountain cities during 1990-2015, showing that the urban land expanded unevenly in terms of spatial distribution. In many cities such as Tonghua, Bijie, Yan'an, Panzhihua, Tongren, Shuangyashan, the new urban area extended along river valleys in a stripped pattern. In several cities including Chongqing, Guiyang, 
Table 2 Annual urban land growth rate (\%) in different periods and the elastic coefficient for all mountain cities of China during 1990-2015

\begin{tabular}{|c|c|c|c|c|c|c|}
\hline \multirow{2}{*}{ City } & \multicolumn{4}{|c|}{ Annual urban land expansion rate (\%) } & \multirow{2}{*}{$\begin{array}{l}\text { Population } \\
\text { growth (\%) } \\
1990-2015 \\
\end{array}$} & \multirow{2}{*}{$\begin{array}{c}\text { Elastic } \\
\text { coefficien } \\
\text { 1990-2015 } \\
\end{array}$} \\
\hline & $1990-2000$ & $2000-2010$ & 2010-2015 & 1990-2015 & & \\
\hline Chengde & 6.50 & 5.06 & 2.07 & 5.02 & 3.59 & 1.40 \\
\hline Yangquan & 2.68 & 0.08 & 4.94 & 2.08 & 2.67 & 0.78 \\
\hline Lvliang & 1.19 & 12.45 & 4.42 & 6.22 & 7.76 & 0.80 \\
\hline Fushun & 1.17 & 1.00 & 0.69 & 1.01 & 0.65 & 1.55 \\
\hline Benxi & 0.66 & 1.49 & 0.27 & 0.91 & 0.74 & 1.23 \\
\hline Liaoyuan & 3.73 & 1.85 & 2.13 & 2.65 & 1.11 & 2.39 \\
\hline Baishan & 3.40 & 1.22 & 1.92 & 2.23 & 3.00 & 0.74 \\
\hline Tonghua & 3.10 & 0.91 & 4.61 & 2.52 & 1.23 & 2.05 \\
\hline Jixi & 3.94 & 2.26 & 7.20 & 3.90 & 0.79 & 4.94 \\
\hline Hegang & 0.94 & 0.10 & 1.10 & 0.63 & 0.87 & 0.72 \\
\hline Shuangyashan & 0.25 & 1.51 & 2.03 & 1.11 & -2.71 & -0.41 \\
\hline Yichun & 2.73 & 5.61 & 23.26 & 7.73 & -0.14 & -55.21 \\
\hline Lishui & 4.58 & 15.42 & 4.97 & 8.87 & 7.28 & 1.22 \\
\hline Sanming & 0.65 & 3.18 & 3.73 & 2.27 & 2.28 & 1.00 \\
\hline Nanping & 6.99 & 3.72 & 16.14 & 7.42 & 2.18 & 3.40 \\
\hline Longyan & 12.81 & 4.38 & 1.07 & 6.98 & 5.50 & 1.27 \\
\hline Yichun & 7.39 & 10.43 & 3.52 & 7.80 & 5.51 & 1.42 \\
\hline Weihai & 8.68 & 12.50 & 5.03 & 9.44 & 7.75 & 1.22 \\
\hline Sanmenxia & 6.31 & 2.43 & 1.19 & 3.71 & 3.62 & 1.02 \\
\hline Huangshi & 0.85 & 7.91 & 1.36 & 3.72 & 2.49 & 1.49 \\
\hline Shiyan & 4.03 & 6.54 & 11.60 & 6.51 & 4.59 & 1.42 \\
\hline Yichang & 2.45 & 7.21 & 9.04 & 5.64 & 5.08 & 1.11 \\
\hline Chenzhou & 5.54 & 6.06 & 3.22 & 5.28 & 6.01 & 0.88 \\
\hline Zhangjaijie & 7.88 & 5.32 & 1.94 & 5.64 & 6.17 & 0.91 \\
\hline Huaihua & 5.96 & 7.39 & 2.31 & 5.78 & 4.50 & 1.28 \\
\hline Yiyang & 2.94 & 7.90 & 1.73 & 4.65 & 6.04 & 0.77 \\
\hline Loudi & 2.25 & 5.23 & 4.85 & 3.96 & 5.50 & 0.72 \\
\hline Shaoguan & 3.66 & 6.59 & 1.00 & 4.28 & 3.97 & 1.08 \\
\hline Wuzhou & 7.99 & 4.06 & 3.12 & 5.42 & 3.42 & 1.58 \\
\hline Hechi & 5.29 & 5.65 & 1.60 & 4.68 & 5.95 & 0.79 \\
\hline Zigong & 4.27 & 3.70 & 6.41 & 4.47 & 2.89 & 1.55 \\
\hline Chongqing & 4.03 & 11.86 & 15.05 & 9.27 & 7.30 & 1.27 \\
\hline Nanchong & 5.29 & 14.40 & 3.23 & 8.41 & 7.52 & 1.12 \\
\hline Luzhou & 6.45 & 8.07 & 8.28 & 7.46 & 5.63 & 1.33 \\
\hline Mianyang & 10.90 & 8.06 & 5.48 & 8.66 & 5.18 & 1.67 \\
\hline Neijiang & 4.37 & 6.31 & 2.91 & 4.85 & 3.86 & 1.26 \\
\hline Leshan & 8.26 & 4.84 & 1.63 & 5.54 & 3.21 & 1.73 \\
\hline Yibin & 8.79 & 4.48 & 3.81 & 6.05 & 5.45 & 1.11 \\
\hline Guangyuan & 8.83 & 8.54 & 0.65 & 7.02 & 4.16 & 1.69 \\
\hline Dazhou & 9.37 & 5.21 & 3.66 & 6.54 & 6.18 & 1.06 \\
\hline Panzhihua & 2.10 & 2.02 & 1.93 & 2.03 & 1.97 & 1.03 \\
\hline Liupanshui & 3.27 & 10.47 & 5.07 & 6.46 & 1.00 & 6.46 \\
\hline Tongren & 3.29 & 13.02 & 9.90 & 8.41 & 5.80 & 1.45 \\
\hline Bijie & 2.74 & 10.03 & 4.71 & 6.00 & 9.32 & 0.64 \\
\hline Guiyang & 7.54 & 6.15 & 7.80 & 7.03 & 4.33 & 1.62 \\
\hline Zunyi & 5.18 & 5.21 & 7.70 & 5.69 & 5.12 & 1.11 \\
\hline Kunming & 6.78 & 11.74 & 1.20 & 7.58 & 4.75 & 1.60 \\
\hline Puer & 3.79 & 12.17 & 1.68 & 6.63 & 5.66 & 1.17 \\
\hline Lincang & 3.28 & 10.06 & 5.39 & 6.37 & 2.94 & 2.17 \\
\hline Shangluo & 5.73 & 5.86 & 4.24 & 5.48 & 6.23 & 0.88 \\
\hline Yan'an & 5.73 & 7.83 & 15.40 & 8.45 & 5.88 & 1.44 \\
\hline Lanzhou & 4.45 & 1.01 & 1.27 & 2.43 & 3.74 & 0.65 \\
\hline Tianshui & 3.20 & 1.74 & 3.73 & 2.72 & 4.04 & 0.67 \\
\hline Longnan & 10.18 & 4.23 & 3.70 & 6.46 & 6.59 & 0.98 \\
\hline Xining & 5.52 & 6.15 & 4.35 & 5.54 & 3.24 & 1.71 \\
\hline
\end{tabular}



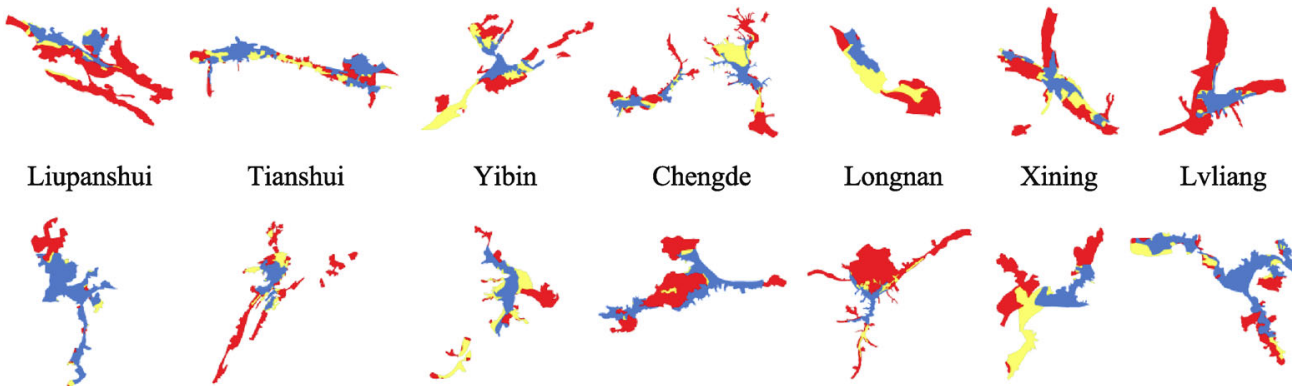

Chengde

Longnan Xining

Lvliang

Shuangyashan

Zunyi

Nanping
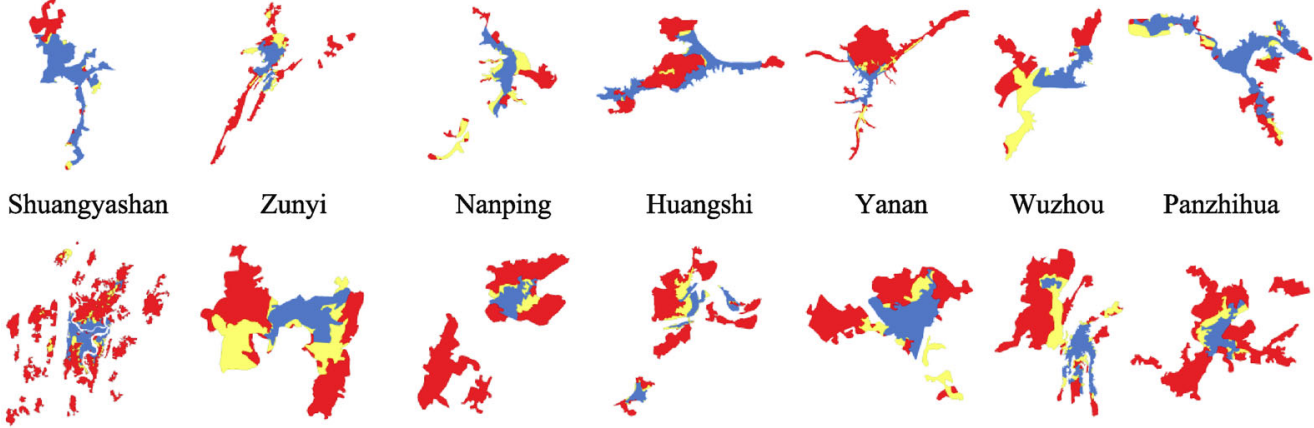

Huangshi

Yanan

Wuzhou

Panzhihua

Chongqing

Dazhou

Lishui
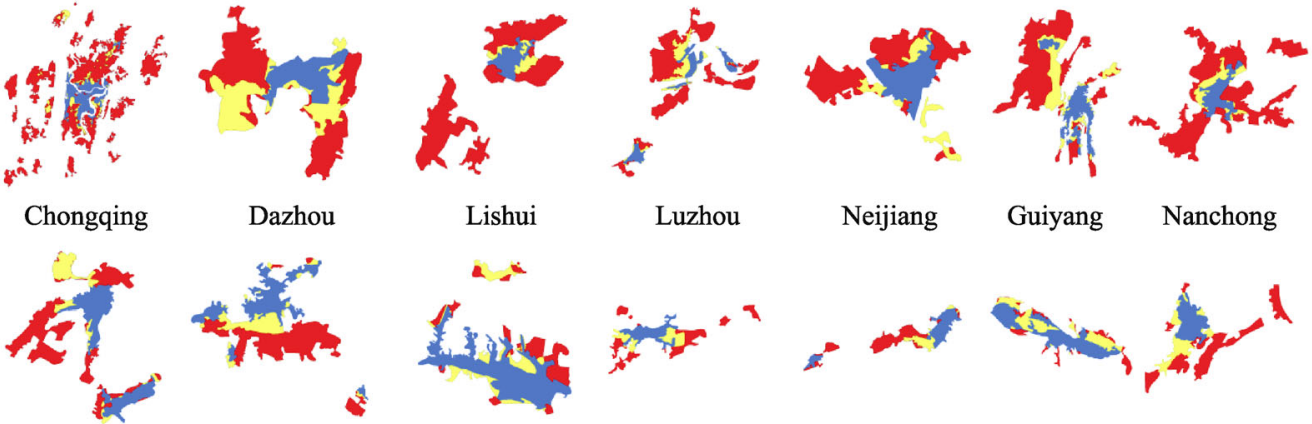

Luzhou

Neijiang

Guiyang

Nanchong

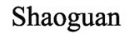

Zigong

Yangquan

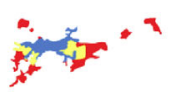
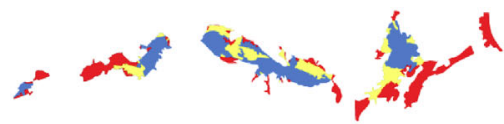

Hechi

$$
\text { Yichun }
$$

Lanzhou

Chenzhou
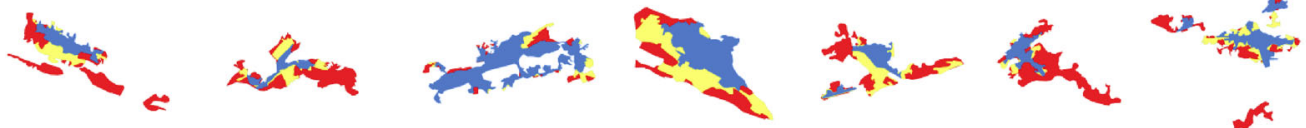

Shangluo

Guangyuan

Fushun

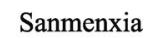

Zhangiiajie

Bijie

Jixi
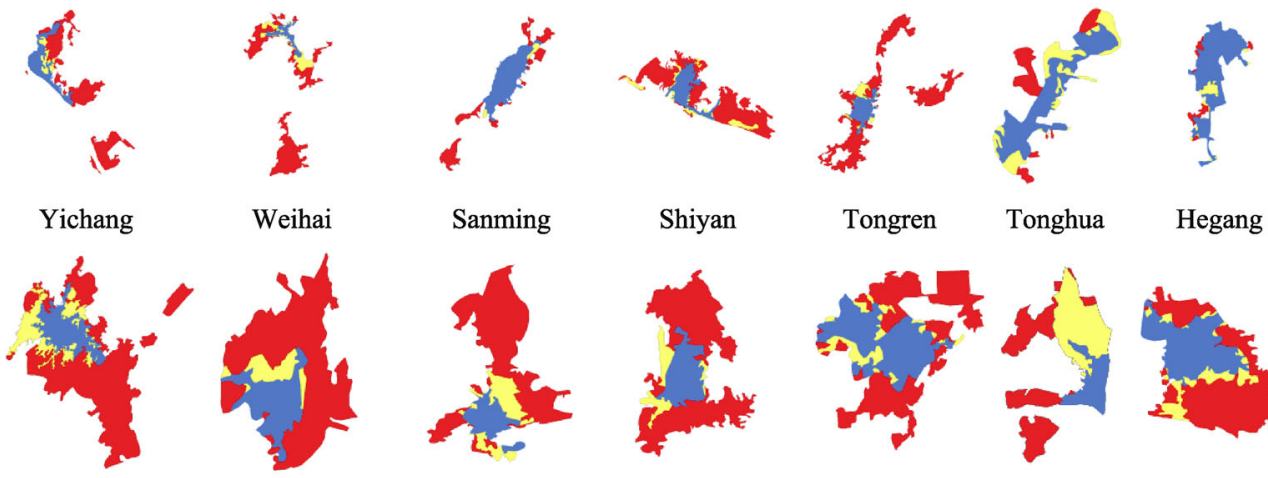

Sanming

Shiyan

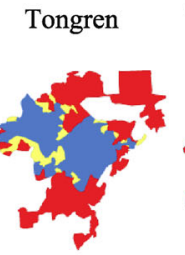

Tonghua

Hegang
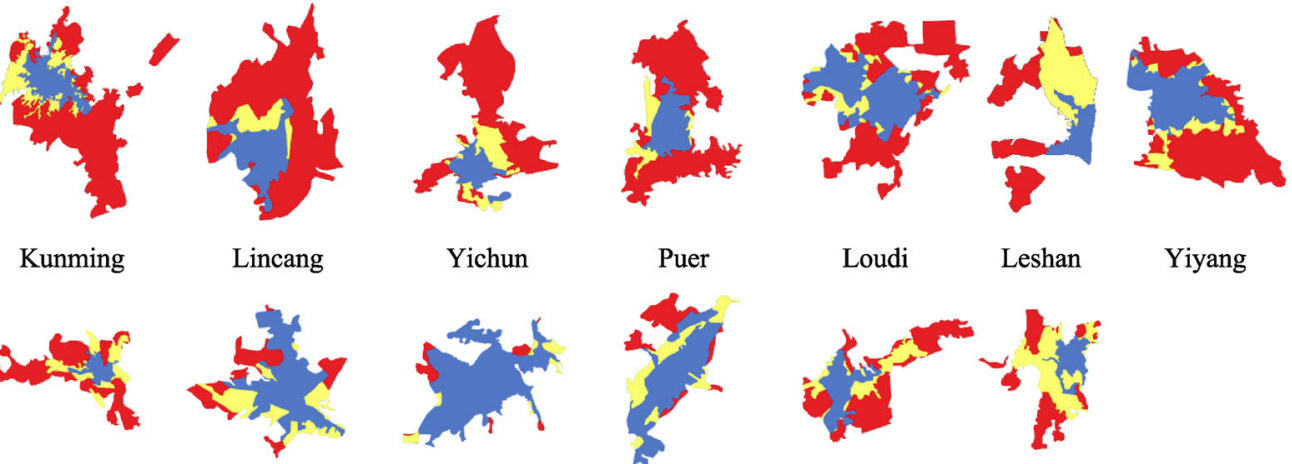

Mianyang

Liaoyuan
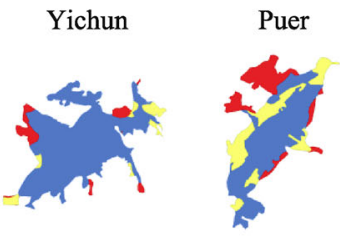

Loudi

Leshan

Yiyang

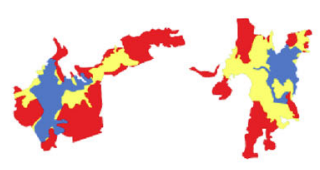

Huaihua

Longyan

Built-up land in 1990

Expanded area during 1990-2000

Expanded area during 2000-2015

Figure 3 Urban land expansion in all mountain cities of China during 1990-2015 (the maps are schematically presented, not at the same scale) 
Nanchong, Lishui, Shaoguan, Hechi and Weihai, the new urban lands were separately developed in different areas with some distance from the old city areas. In cities including Lincang, Yiyang, Yichun, Pu'er, Longyuan, Baishan and Sanmenxia, the new urban area was continuously extended from the old city, because these cities are generally located in mountain basins, and thus there is continuous gentle land near the cities suitable for urban development.

The urban land area of most mountain cities is spatially discontinuous, irregular and incompact, and thus the compactness index was very low. The average index value was only $0.36,0.34,0.34$ and 0.33 in 1990, 2000, 2010 and 2015, respectively, much lower than the

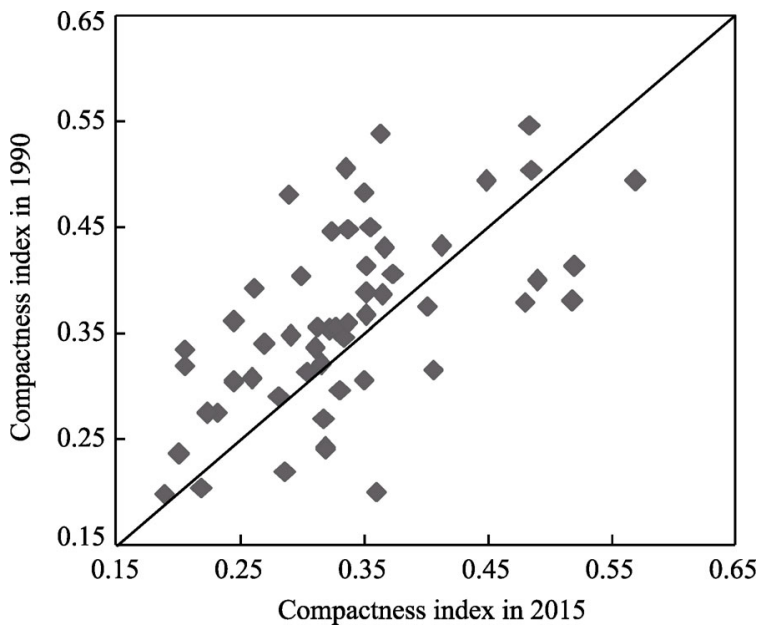

Figure 4 Schematic comparison of city compactness index of mountain cities in China in 1990 and 2015 value of 0.375 to 0.739 for other cities reported in different studies (Liu et al., 2014; Pan et al., 2015). Of the 55 mountain cities, only 17 in 1990, 15 in 2000, 13 in 2010 and 12 in 2015 showed a compactness index value above 0.4, while 18 cities were found with the value below 0.3 in 2015 . Compared to 1990, the compactness index in 2015 apparently decreased in most mountain cities (Figure 4), inferring that the suitable land surrounding the city could be becoming less available, and thus the terrain restriction on the urban layout was stronger.

\section{Factors affecting the urban land expansion}

This section analyzed the influences of policy, adjustment of urban administrative division, terrain and socio-economic factors on the urban land change during 1990-2015.

\subsection{Urban development policy}

As indicated by several studies (Huang et al., 2012; Obeso Muniz et al., 2017), the government policies have a great influence on the urban development, including industry policy, fiscal policy, land use policy, regional development policy, and urban planning policy. For the mountain cities involved in this study, changes in the urban land growth rate between different stages could be mainly caused by the national urban development policy. In 1990, the Chinese government issued the City Planning Law, to "strictly control the size of large cities and rationally develop medium-sized cities and small cities". Meanwhile, various policies were simultaneously adopted to control the over-expansion of urban land, particularly that of large cities. After ten years, this control was relaxed in 2000 by the policy adjusted to "adhere to the coordinated development of large, medium and small cities, and small towns", which was released in the China's 10th Five-Year Plan (2001-2005) and the Report at 16th CPC National Congress in 2002. With this relaxed control, many cities enhanced the development, resulting in the much quicker urban land expansion after 2000. 


\subsection{Changes to administrative divisions}

Changes to the administrative divisions involve the adjustment in administrative rank, economic status and territorial governance (Cartier, 2016). These changes were often associated with new area development, and thus greatly stimulated the expansion of city range (Wang et al., 2016). During the study period, several mountain cities adjusted the city scope to extend the urban space. Such a well-known city is Chongqing. In 1997, it was approved as the fourth municipality directly under the central government, and since then the urban growth rate was doubled (Table 2). Another case is Kunming. After the new planning was implemented in 1998 (Luo et al., 2015), Kunming city kept a high land expansion rate of more than 10\% per year during 2000-2010. In several other cities, such as Tongren and Yan'an, the urban land showed an accelerated expansion after the new district development was implemented in 2006 and 2012, respectively.

\subsection{Terrain conditions}

As mentioned in Section 3.2, terrain conditions had a significant influence on the shape and layout of mountain cities, but its impact seemed insignificant on the city size and expansion speed of the urban land area. Terrain characteristics indicated by the slope steepness and elevation were not found to have a relevance to the total urban land area and urban land changes by paired correlation. This was also found in a previous study for all cities in China (Huang et al., 2007). The reason might be that the terrain limitations can be largely removed by engineering measures such as building industrial terraces, truncating small hills, which has been practiced in mountain cities such as Yan'an and Tongren in recent years. Another reason is that the city can select a new area to break through the shackles of insufficient space around the built-up area for urban development (Zhang et al., 2015).

Since larger investment is needed to realize the land expansion, the mountain cities generally showed a stronger tendency to more efficiently use the urban space than to expand the area, compared to other cities in China. From this angle, terrain condition could have a significant restriction on the development of mountain cities. For instance, the mean land area per capita in the mountain cities was $74.6 \mathrm{~m}^{2}$ in $1990,65.8 \mathrm{~m}^{2}$ in $2000,87.1 \mathrm{~m}^{2}$ in 2010 , and $97.3 \mathrm{~m}^{2}$ in 2015 , all below the target area $\left(100 \mathrm{~m}^{2}\right.$ per capita) of urban land use control specified by the Chinese government (MLR, 2014). The cities with the urban land area below $100 \mathrm{~m}^{2}$ per capita covered $84 \%$ of the mountain cities in 1990 , and further increased to $95 \%$ in 2000 . After then, the proportion decreased to $75 \%$ in 2010 and further to $58 \%$ in 2015 , implying that the urban land expansion was highly accelerated in many mountain cities during the last 15 years. For all cities in China, the mean land area per capita was $87.1 \mathrm{~m}^{2}$, $107.1 \mathrm{~m}^{2}, 117.0 \mathrm{~m}^{2}$ and $113 \mathrm{~m}^{2}$ in the corresponding year (MOHURD, 2016; Wang et al., 2012; Yang et al., 2013), which is expected to reach $165 \mathrm{~m}^{2}$ in 2020 (Tan et al., 2010).

\subsection{Socio-economic factors}

The ridge regressions indicated that total GDP, urban population, and green land area had a significant relevance to the urban land area in the four years. Road land area appeared to be a significant contribution factor in 2000 and 2015 (Table 3). Urban population was the most important factor influencing urban land area: the contribution coefficient was 0.296 in 1990, implying that the urban land area would increase by $2.96 \%$ with a growth of $10 \%$ in popula- 
tion. After 1990, its influence showed a slightly declining trend, from 0.29 in 2000 to 0.276 in 2010 and 0.266 in 2015. Total GDP and green land area were also significant to the urban area, but their significance, i.e., the contribution coefficient decreased, from 0.258 and 0.279 in 1990 to 0.136 and 0.177 in 2015 , respectively. Total urban road area was not found to have a significant relevance to the urban land area in 1990, but in 2015, it became the most important contributor, implying that transportation construction was becoming more important in promoting urban development. Assets investment was found to have a significant relevance only in 2010 .

Table 3 Regression results between urban land area and the driving factors in four years

\begin{tabular}{|c|c|c|c|c|}
\hline Factors & 1990 & 2000 & 2010 & 2015 \\
\hline \multirow{2}{*}{ LnGDP } & $0.258 * *$ & $0.189 * *$ & $0.139 * * *$ & $0.136 * *$ \\
\hline & $(2.567)$ & $(2.133)$ & $(2.876)$ & (3.109) \\
\hline \multirow{2}{*}{ LnPOP } & $0.296 * * *$ & $0.29 * * *$ & $0.276^{* * *}$ & $0.266^{* * *}$ \\
\hline & $(2.9)$ & (3.242) & $(5.323)$ & $(4.763)$ \\
\hline \multirow{2}{*}{ LnGR } & $0.279 * * *$ & $0.162 *$ & $0.192 * * *$ & $0.177 * *$ \\
\hline & (3.314) & (1.987) & (3.6) & (3.077) \\
\hline \multirow{2}{*}{ LnINV } & 0.074 & 0.113 & $0.133 * *$ & 0.0308 \\
\hline & $(0.742)$ & (1.337) & $(2.555)$ & $(0.605)$ \\
\hline \multirow{2}{*}{ LnRDA } & 0.039 & $0.172 *$ & $0.231 * * *$ & $0.312 * * *$ \\
\hline & $(0.452)$ & $(1.916)$ & $(4.24)$ & $(5.563)$ \\
\hline$R^{2}$ & 0.78 & 0.751 & 0.897 & 0.845 \\
\hline Adjusted $\mathrm{R}^{2}$ & 0.753 & 0.72 & 0.886 & 0.829 \\
\hline F statistics & $29.14^{* * *}$ & $24.767 * * *$ & $82.117 * * *$ & $53.375 * * *$ \\
\hline
\end{tabular}

Note: $* * *, * * *$ represent the significance level of $10 \%, 5 \%$ and $1 \%$, respectively. The value in parentheses is the $t$ test.

For the urban land expansion, urban population growth (Ln $\triangle \mathrm{POP})$ and urban road construction (Ln $\triangle \mathrm{RDA}$ ) were found to be the significant contributors in the four periods (Table 4). During the study period of 1990 to 2015, changes in GDP (Ln $\Delta$ GDP) showed a

Table 4 Regression results between urban land increase and the driving factors during three periods

\begin{tabular}{|c|c|c|c|c|}
\hline Factors & 1990-2000 & 2000-2010 & $2010-2015$ & 1990-2015 \\
\hline \multirow{2}{*}{$\operatorname{Ln} \Delta \mathrm{GDP}$} & 0.073 & 0.0635 & 0.121 & $0.197 * *$ \\
\hline & $(0.713)$ & $(0.437)$ & (1.279) & $(2.544)$ \\
\hline \multirow{2}{*}{$\mathrm{Ln} \triangle \mathrm{POP}$} & $0.319 * * *$ & $0.334 * * *$ & $0.215^{* *}$ & $0.186^{* *}$ \\
\hline & (2.99) & $(2.767)$ & (2.188) & $(2.257)$ \\
\hline \multirow{2}{*}{$\operatorname{Ln} \Sigma I N V$} & 0.144 & 0.0929 & $0.259 * *$ & 0.101 \\
\hline & (1.386) & $(0.929)$ & $(2.561)$ & (1.224) \\
\hline \multirow{2}{*}{$\operatorname{Ln} \Delta \mathrm{RDA}$} & $0.225 * *$ & $0.284 * *$ & $0.232 * *$ & $0.365 * * *$ \\
\hline & $(2.143)$ & $(2.281)$ & $(2.442)$ & $(4.272)$ \\
\hline $\mathrm{R}^{2}$ & 0.457 & 0.461 & 0.516 & 0.688 \\
\hline Adjusted $\mathrm{R}^{2}$ & 0.406 & 0.411 & 0.472 & 0.658 \\
\hline F statistics & $8.861 * * *$ & $9.404 * * *$ & $11.74 * * *$ & $23.191 * * *$ \\
\hline
\end{tabular}

Note: $* * *, * * *$ represent the significance level of $10 \%, 5 \%$ and $1 \%$, respectively. The value in parentheses is the $t$ test. 
significant contribution to the urban land expansion, and in the other periods, the contribution was not significant. In 2010-2015, total fixed assets investment ( $\operatorname{Ln} \Sigma I N V)$ had a significant contribution to the urban land increase (Table 3), implying that the low-slope hilly and mountain land development promoted by the government since 2011 (MLR, 2011) obviously stimulated the land expansion of mountain cities. During the 25 years from 1990 to 2015 , land expansion of the mountain cities was mainly stimulated by urban population growth, road construction and GDP growth, which can explain about $70 \%$ of the urban land increase. Income and foreign investment, and slope steepness and elevation were not found to have a significant relevance to the urban size or urban land expansion.

\section{Discussion}

\subsection{Spatio-temporal variation of urban land expansion rates}

From 1990 to 2015, the total built-up land area of the mountain cities increased by 3.87 times, or $5.56 \%$ per year. Affected by the urban development policy, the urban land expansion showed a periodic characteristic, with the annual growth rate varying from $4.35 \%$ during 1990-2000 to $6.47 \%$ during 2000-2010 and then to $6.2 \%$ during 2010-2015. This phased difference was also observed for the urban land change in other cities of China, but the difference extent was much lower in the mountain cities. For instance, Liu et al. (2014) found that the built-up land expansion rate of China during 2000-2010 was 2.14 folds of that during 1990-2000. According to the statistics, the annual growth rate in China's total urban area was $6.95 \%$ during $2000-2010$, but it was only $2.12 \%$ during $1990-2000$. This infers that the policy adopted in 1990 to control the over-expansion of large cities had a less impact on the mountain cities, because the cities are mostly small and medium-sized cities.

The urban land expansion showed an obvious regional difference, with an annual growth rate during the 25 years ranged from above $6.0 \%$ in the eastern and western regions of China, to $4.93 \%$ in the central region, and then apparently decreased to $2.17 \%$ in northeastern China (Table 1). For all cities in China, the urban land expansion showed a similar regional variation (An et al., 2012; Wen et al., 2016). As for individual mountain cities, the urban growth rate varied greatly, with the area increasing by 5.40-9.54 times in 15 cities and only $17.1 \%-31.7 \%$ in 4 cities in northeastern China. For the quickly growing cities, the land expansion was greatly promoted by the changes to administrative divisions and new district development, while for the slowly ones, the low land expansion was mainly due to the shrinkage of urban population associated with low economic development. Several similar cases were reported in previous studies. For instance, in Shanghai, the urban land area increased by $120 \%$ from 1990 to 2000 after the Pudong New Area was initiated in 1990 (Zhang et al., 2015). In Tianjin, the urban land was expanded by 78\% during 2000-2010, mainly as a result of the Binhai New Area development after 2000 (Zhang et al., 2016).

\subsection{Urban land expansion and population growth}

Total growth of urban land for the mountain cities was much higher than that of urban population, with the mean elastic coefficient of 1.44 from 1990 to 2015 . However, the urban expansion for the mountain cities as a whole was lower compared with other cities in China. 
A study indicated that the mean elastic coefficient for all cities in China was 1.53 during 1990-1999 and 2.25 during 1999-2009 (An et al., 2012), showing a much faster growth rate in the urban land area compared with population. As for specific cities, about half of the mountain cities showed an above $20 \%$ quicker growth in the urban land area than population. However, over $65 \%$ of the cities in China showed a much faster growth of urban land than that of population (Yang et al., 2013; Zou et al., 2015). In general, the urban land use intensity in the mountain cities was rather high, for instance, the mean land area per capita for the 55 mountain cities was $97.3 \mathrm{~m}^{2}$ in 2015 , while it was only $86.1 \%$ of the mean value $\left(113 \mathrm{~m}^{2}\right)$ for all cities in China in 2015 (MOHURD, 2016).

\subsection{Urban land expansion mechanism}

In most mountain cities, the terrain seems to have no significant influence on the urban land expansion rate, which is in accordance with the results reported by Huang et al. (2007); however, terrain condition significantly determined the main direction of urban expansion (Figure 3), and thus had an apparent impact on the city shape and sprawl pattern, as indicated by the compactness of the mountain cities that was generally very low (Figure 4). Similar results were also obtained by previous studies (Pan et al., 2015; Wang et al., 2005) that the compactness of the cities in plain areas of northern China was higher than that of the cities in southern China, as they are often restricted by the surrounding hills or rivers and lakes. For some cities such as Lanzhou, the urban development could be strongly restricted by the surrounding mountains, as the urban land increased by only $28 \mathrm{~km}^{2}$ during 2000-2015.

For all cities in China, population and GDP growth were acknowledged as the main driving factors (Tan et al., 2003; Zhang et al., 2011). As for mountain cities, except policy and changes to administrative divisions, urban population growth, GDP growth and urban road construction were identified as the major driving factors of the urban land expansion from 1990 to 2015, and fixed asset investment made a great contribution to the urban land expansion in recent 5 years of 2010-2015. Other factors were not found to have a significant relevance to the urban land expansion in the mountain cities. It should be noted that the interpreted urban land only covered the built-up areas in the city districts, while the socio-economic data were collected for the whole city. Therefore, the space extent for the data may not be exactly matched. The urban population was all non-agricultural population as registered in the city, not including the floating population, which could cause bias errors on the results, particularly for per capita urban land area.

\section{Conclusions}

The study results indicate that most of mountain cities maintained a quick growth during 1990-2015, and after 2000 the urban expansion was markedly accelerated. Five factors identified in this study stimulated this quick growth, including policy, adjustment of administration devisions, urban population and GDP growth, and urban road construction. Terrain conditions were not found to have a significant influence on the urban land expansion rate of mountain cities, but had a great impact on the city shape and compactness. Due to terrain restriction, the mountain cities presented a stronger tendency to more efficiently use the urban space than to expand the area, thus showed higher urban land use efficiency than cities 
in plain areas.

During 1990-2015, total built-up land area of the mountain cities increased by 3.87 folds. However, this quick urban land growth could be reasonable for the mountain cities as a whole, as the urban land area per capita was still within the government control target. Considering their important role in absorbing the rural population and promoting the regional development, appreciate financial supports and preferential policies should be adopted to enhance the development of mountain cities. As these cities are mostly surrounded by mountains, the urban development should be aimed at building an ecological and livable city, instead of damaging the mountain landscape and natural ecosystems.

\section{References}

An Qian, Li Xiaojian, Lv Kewen, 2012. A research on the spatial structure and efficiency of China's expansion of urban built-up area (1990-2009). Economic Geography, 32(6): 37-45. (in Chinese)

Barcena Mj, Menendez P, Palacios Mb et al., 2014. Alleviating the effect of collinearity in geographically weighted regression. Journal of Geographical Systems, 16(4): 441-466.

Cao Yingui, Bai Zhongke, Zhou Wei et al., 2016. Analyses of traits and driving forces on urban land expansion in a typical coal-resource-based city in a loess area. Environmental Earth Sciences, 75(119116).

Cartier Carolyn, 2016. A political economy of rank: The territorial administrative hierarchy and leadership mobility in urban China. Journal of Contemporary China, 25(100): 529-546.

Chen Jianglong, Gao Jinlong, Chen Wen, 2016. Urban land expansion and the transitional mechanisms in Nanjing, China. Habitat International, 53: 274-283.

Chen Wei, 2001. Discrimination of the concept of our country's mountainous city. Huazhong Architecture, 19(3): 55-58. (in Chinese)

Chi Wenfeng, Shi Wenjiao, Kuang Wenhui, 2015. Spatio-temporal characteristics of intra-urban land cover in the cities of China and USA from 1978 to 2010. Journal of Geographical Sciences, 25(1): 3-18.

Guo Liying, $\mathrm{Hu}$ Yecui, 2005. Integrated utilization models of land resources of the mountainous type city in southeast coastal areas. Journal of Mountain Science, 23(1): 121-125. (in Chinese)

Huang Guangyu, 2006. Theory of Mountain Urbanology. Beijing: China Building Industry Press. (in Chinese)

Huang Jikun, Zhu Lifen, Deng Xiangzheng, 2007. Regional differences and influencing factors of urbanland expansion in China. Science in China (Ser. D: Earth Sciences), 37(9): 97-103. (in Chinese)

Huang Xiangmei, Hong Shiqin, 2012. The effects of governments applying on distribution of city sizes. Journal of Lanzhou Commercial College, 28(1): 49-57. (in Chinese)

Li Cheng, Zhao Jie, Xu Yong, 2017. Examining spatiotemporally varying effects of urban expansion and the underlying driving factors. Sustainable Cities and Society, 28: 307-320.

Li Hui, Wang Li, Ren Qilong et al., 2016. Urban land expansion characteristics and driving factors in northeast China. Geospatial Information, 4(14): 84-89. (in Chinese)

Li Mingcai, Guo Jun, Xiong Mingmin, 2011. Expansion characteristics and its driving forces of built-up area in Tianjin based on remote sensing and GIS. Chinese Journal of Ecology, 30(7): 1521-1528. (in Chinese)

Lin Xueqin, Wang Yang, Wang Shaojian et al., 2015. Spatial differences and driving forces of land urbanization in China. Journal of Geographical Sciences, 25(5): 545-558.

Liu Fang, Zhang Zengxiang, Shi Lifeng et al., 2016. Urban expansion in China and its spatial-temporal differences over the past four decades. Journal of Geographical Sciences, 26(10): 1477-1496.

Liu Gaoxiang, 2009. Mountain city growing space planning research base on theory of man-land relationship [D]. Chongqing: Chongqing University. (in Chinese)

Liu Jiyuan, Kuang Wenhui, Zhang Zengxiang et al., 2014. Spatiotemporal characteristics, patterns, and causes of land-use changes in China since the late 1980s. Journal of Geographical Sciences, 24(2): 195-210.

Liu Qinping, Yang Yongchun, Fu Dongxia et al., 2014. Urban spatial expansion based on DMSP_OLS nighttime light data in China in 1992-2010. Scientia Geographica Sinica, 34(2): 4-11. (in Chinese)

Luo Zhendong, Wang Xin, Geng Lei, 2015. Administrative division adjustment in metropolitan area of China: Stages and characteristics in the acceleration period of urbanization. Planning Studies, 35(2): 44-49, 64. (in Chinese)

Marshall Juliand, 2007. Urban land area and population growth: A new scaling relationship for metropolitan expansion. Urban Studies, 44(10): 1889-1904. 
Ministry of Housing and Urban-Rural Development of the People's Republic of China (MOHURD), 2016. Urban and Rural Construction Statistics Bulletin of 2015. [viewed 1 October 2017]. Available from: http://www.mohurd.gov.cn/xytj/tjzljsxytjgb/tjxxtjgb/201607/t20160713_228085.html. (in Chinese)

Ministry of Land and Resources of the People's Republic of China (MLR), 2011. The MLR plans to strengthen the use of low-slope hilly Land and mountain land. [viewed 1 October 2017]. Available from: http://www.mlr.gov.cn/xwdt/mtsy/201110/t20111008_981187.htm. (in Chinese)

Ministry of Land and Resources of the People's Republic of China (MLR), 2014. Notice on strengthening and managing the strictest farmland protection system. [viewed 1 October 2017]. Available from: http://www.mlr.gov.cn/zwgk/zytz/201402/t20140220_1304242.htm. (in Chinese)

Mizutani Chiaki, 2012. Construction of an analytical framework for polygon-based land use transition analyses. Computers Environment and Urban Systems, 36(3): 270-280.

Obeso Muniz Icaro, Fernandez Garcia Felipe, 2017. Recent urban development in Gijon (Spain). Historic aerial photography as a tool for sustainability assessment of the process. Cities, 67: 1-8.

Pan Jinghu, Dai Weili, 2015. Spatial-temporal characteristics in urban morphology of major cities in China during 1990-2010. Economic Geography, 35(1): 44-52. (in Chinese)

Tan M H, Li X B, Xie H et al., 2005. Urban land expansion and arable land loss in China: A case study of Beijing-Tianjin-Hebei region. Land Use Policy, 22(3): 187-196.

Tan Minghong, 2017. Uneven growth of urban clusters in megaregions and its policy implications for new urbanization in China. Land Use Policy, 66: 72-79.

Tan Minghong, Li Xiubin, 2010. Characteristics of urban land per capita of major countries in the world and its implications for China. Journal of Natural Resources, 25(11): 1813-1822. (in Chinese)

Tan Minghong, Li Xiubin, Lu Changhe, 2003. An analysis of driving forces of urban land expansion in China. Economic Geography, 23(5): 635-639. (in Chinese)

Tong Luyi, Hu Shougeng, 2016. Characterizations of urban sprawl in major Chinese cities. Resources science, 38(1): 50-61. (in Chinese)

Wang Chenglong, Liu Hui, Zhang Mengtian, 2016. The influence of administrative boundary on the spatialexpansion of urban land:A case study of Beijing-Tianjin-Hebei urban agglomeration. Geographical Research, 35(1): 173-182. (in Chinese)

Wang Jun, Zhao Min, Li Xinyang, 2012. Disscussion on ideas concerning formation of new planning standard of development land in China. City Planning Review, 36(4): 54-60. (in Chinese)

Wang Xinsheng, Liu Jiyuan, Zhuang Dafang et al., 2005. Spatial-temporal changes of urban spatial morphology in China. Acta Geographica Sinica, 60(3): 42-50. (in Chinese)

Wen Qingke, Zhang Zengxiang, Shi Lifeng et al., 2016. Extraction of basic trends of urban expansion in China over past 40 years from satellite images. Chinese Geographical Science, 26(2): 129-142.

Yang Yanzhao, Feng Zhiming, Zhao Yande et al., 2013. Coordination between urban land expansion and populationgrowth in China. Geographical Research, 32(9): 1668-1678. (in Chinese)

Yu Wenjuan, Zhou Weiqi, 2017. The spatiotemporal pattern of urban expansion in China: A comparison study of three urban megaregions. Remote Sensing, 9(451).

Yu Xi, Zhang Bingqi, Li Qiang et al., 2016. A method characterizing urban expansion based on land cover map at $30 \mathrm{~m}$ resolution. Science China-Earth Sciences, 59(9): 1738-1744.

Zhang Li, Lei Jun, Li Xuemei et al., 2011. The features and influencing factors of urban expansion in China during 1997-2007. Progress in Geography, 30(5): 607-614. (in Chinese)

Zhang Xiaoran, Bai Zhongke, Fan Xiang et al., 2016. Urban expansion process, pattern, and land use response in an urban mining composited zone from 1986 to 2013. Journal of Urban Planning and Development, 142(4): 04016014.

Zhang Xiaotong, 2007. Econometrics. Tianjin: Nankai University Press. (in Chinese)

Zhang Yue, Ye Gaobin, Yao Shimou, 2015. The interactive study on new town construction of development zone and urban expansion: Taking Shanghai, Hangzhou and Nanjing as an example. Economic Geography, 35(2): 84-91. (in Chinese)

Zhang Zengxiang, Li Na, Wang Xiao et al., 2016. A comparative study of urban expansion in Beijing, Tianjin and Tangshan from the 1970s to 2013. Remote Sensing, 8(6): 496.

Zhou Guohua, He Yanhua, 2007. The influencing factors of urban land expansion in Changsha. Journal of Geographical Sciences, 17(4): 487-499.

Zou Jinlang, Wu Qun, 2015. Variance analysis of decoupling population growth from construction land expansion in the cities of China. In: National Land Resources Development and Renovation and New Urbanization Construction Symposium. Anyang: Xinhua Publishing House. (in Chinese) 